\title{
Risk Factors for Problematic Alcohol Use Among Male Waste Pickers and Caddies in Johannesburg, South Africa: A Cross-Sectional Study
}

Simbulele Onesimo Mdleleni ( $\sim$ simbulele.mdleleni@gmail.com )

Sangyo Ika Daigaku Daigakuin Igaku Kenkyuka

\section{Kerry Wilson}

National Institute for Occupational Health

\section{Vusi Ntlebi}

National Institute for Occupational Health

\section{Felix Made}

National Institute for Occupational Health

\section{Tahira Kootbodien}

National Institute for Occupational Health

\section{Nonhlanhla Tlotleng}

National Institute for Occupational Health

Matimba Makhubele

National Institute for Occupational Health

Nisha Naicker

National Institute for Occupational Health

\section{Research article}

Keywords: Alcohol use/abuse, drinking behaviour/patterns, informal work/sector, Common mental disorders, substance abuse

Posted Date: August 13th, 2020

DOl: https://doi.org/10.21203/rs.3.rs-52888/v1

License: (c) (i) This work is licensed under a Creative Commons Attribution 4.0 International License. Read Full License 


\section{Abstract}

\section{Background}

Informal workers may be prone to problematic substance use due to many factors, including adverse working conditions and low income. Therefore, research must be conducted to improve the lifestyle of this vulnerable group of workers. This research aimed to assess problematic alcohol use and risk factors among male informal workers in Johannesburg.

\section{Methods}

Two groups of informal workers, waste pickers, and golf caddies were included. Alcohol use was measured using the World Health Organization (WHO) Alcohol Use Disorder Identification Test (AUDIT) tool. The WHO self-reporting questionnaire (SRQ) for common mental health disorders (CMD) was used to assess mental health. Data analysis included demographic analysis of the participants, assessment of substance use, and the ascertainment of drinking problem risk factors.

\section{Results}

The study consisted of 514 participants, of which $48.4 \%$ were golf caddies and $51.6 \%$, waste pickers. Most participants were younger than 40 years (50.9\%). Over half of the participants (54.7\%) were alcohol consumers and $74.1 \%$ were smokers. Over $60 \%$ of the participants who were alcohol consumers had a probable drinking problem. The prevalence of mental distress in the study group was $27 \%$ mental distress.

Unstratified regression results showed that informal workers positive for mental distress were more likely to have a probable drinking problem $(\mathrm{aOR}=1.06 ; 95 \% \mathrm{Cl}: 1.01-1.11)$. Informal workers aged $30-40$ years $(\mathrm{aOR}=2.06 ; 95 \% \mathrm{Cl}: 1.13-3.75)$, and those who were smokers $(\mathrm{aOR}=2.25 ; 95 \% \mathrm{Cl}: 1.33-3.80)$ were also more likely to have a probable drinking problem.

\section{Conclusion}

Problematic drinking amongst informal workers in this study was common along with smoking. Problematic alcohol use was associated with the type of informal work, mental distress, age, and smoking. Measures such as providing counselling services to informal workers and improvement of working conditions are needed to change the behaviours of this vulnerable group.

\section{Introduction}

The International Labour Organisation (ILO) defines an "informal economy" based on two methods. The first method is based on whether an enterprise in which workers are employed is registered with the authorities. The more recent definition of the second method covers all work that is not covered by formal arrangements - own account work, employment in the informal sector, and employment in the formal 
sector that is not regulated or protected $(1-3)$. The informal economy is often characterised by lowincome opportunities, temporary employment, low productivity, and small-scale enterprises using labourintensive activities (4). South Africa (SA) is characterised by a relatively small economy, high levels of unemployment, high poverty levels, and high-income inequality leading to informal employment $(1,2)$. In 2018 , the informal sector comprised approximately 2.5 million workers and business owners (5).

Golf is an important industry in SA (6). In addition to carrying golfers' bags, caddies are expected to clean golf clubs; wash the dirt off the golf balls, and offer helpful advice to the golfers (7). Waste picking and solid waste recycling are a prominent part of the urban landscape in many cities in the country (8). Waste pickers are valuable contributors to urban sustainability and recycling (9). Waste pickers collect waste by collecting it from public places such as garbage dumps and streets (10). Unlike workers in the formal sector, golf caddies and waste pickers lack guaranteed wages, benefits, and protection (7).

Workers in the informal employment sector are generally not protected by employment legislation (11). This lack of employment protection may lead to adverse mental and physical health (11). In a study conducted among Brazilian formal and informal employees, common mental disorders (CMD) had a higher prevalence in informal employees before and after adjusting for sex, age, marital status, and migration (OR 2.16, 95\% Cl 1.3-3.7) (11).

SA, as a low-middle income country has been reported to be one of the countries with high levels of alcohol consumption in a small proportion of citizens by the World Health Organization (WHO) (12). In 2016, the adult per capita (APC) alcohol consumption in SA was 9.3 litres (ranked 52nd in the world) of pure alcohol (12). Amongst alcohol consumers in the African Region, SA has the third-highest APC after Eswatini and Namibia (12). Between 2014 and 2015, South Africa reported a prevalence of heavy episodic drinking (binge drinking) in the whole population of $43.0 \%$ in both sexes (13). Amongst drinkers, males had a high prevalence of $48.2 \%$ of binge drinking (13). Previous studies have linked informal work to smoking and drinking $(14,15)$.

In American rural areas, alcohol consumption has been identified as an influence on one's mechanisms of coping with distressful life events such as unemployment and poverty (12). There is evidence that both smoking and alcohol also contribute to the lifestyle associated health-inequalities in the poor in South Africa (16).

WHO defines a standard drink as a $10 \mathrm{~g}$ of pure alcohol, and advises that both men and women not to drink more than two standard drinks a day (17). Problematic alcohol use is defined as heavy drinking or drinking that is accompanied by unpleasant consequences $(18,19)$. Alcohol use disorders include alcohol dependence, high intensity-drinking, difficulty cutting back, life interference, and or hazardous use such as binge drinking $(20,21)$. Depression, anxiety, difficulty sleeping, suicidal thoughts, and attempts, as well as abuse of other notorious drugs, have been associated with alcohol dependency (22).

The objective of this paper is to describe problematic alcohol use among male informal workers in Johannesburg and to identify risk factors associated with problematic alcohol use. 


\section{Methods}

\section{Primary Studies}

\section{The Waste pickers study}

The Johannesburg waste pickers study aimed to generate new knowledge by achieving a greater understanding of the nature and depth of potential health risks and outcomes posed to people informally working on landfills. The cross-sectional study surveyed 249 male waste pickers (23). Participants were invited from two of the largest landfill sites in Johannesburg.

\section{The Golf Caddies study}

This cross-sectional study aimed to investigate the working conditions (exposures) and health outcomes, as well as health care access, associated with working as a caddie at golf courses in Johannesburg. The participants were invited from six randomly chosen golf clubs in Johannesburg, South Africa.

Both studies were conducted by the National Institute for Occupational Health (NIOH), Epidemiology and Surveillance Section. After the acquisition of informed consent, structured face-to-face interviews using a structured questionnaire were performed by trained fieldworkers, with local language translation where possible, using electronic RedCap data processing software. Basic health screening was also conducted by trained nurses in the field offices.

\section{Secondary Analysis}

\section{Measures}

This study used data from the National Institute for Occupational Health (NIOH), Epidemiology and Surveillance Section to determine risk factors for problematic alcohol use among male informal workers in Johannesburg.

Demographic information. The demographic characteristics of the participants analysed were age, nationality, socioeconomic proxies such as education level, cooking source (eg. electricity, paraffin), water source, toilet type, and average income earned monthly. The average amount of money reported spent on lifestyle habits such as drinking and smoking was compared between the two groups of informal workers. Work stress was defined differently for caddies and waste pickers. In the golf caddies study, work stress was defined as feeling intimidated by golf players. In the waste pickers study, it was defined as experiencing physical violence at work with other waste pickers or with security guards. No female caddies were present at the visited golf courses; therefore, this secondary analysis only includes male participants. 
For data analysis purposes, age was categorised into $<30,30-40,41-50$, and $>50$ years old as few caddies were less than 30 years and few waste pickers were less than 20 years of age. However, for regression purposes (Table 5), age was categorised differently for caddies and waste pickers due to differences in distribution: caddies "41-50 years" and waste pickers "41->50 years". The nationality of the participants was considered as either South African or non-South African. The participants' education status was defined as "no schooling", "primary school", "secondary school", and "tertiary school levels". The water source was grouped into "household tap", "communal tap", and "other" (river, dam or reservoir). The toilet type was categorised into "household flushing toilet", "communal toilet", and "other" (pit latrine, chemical). The average monthly income was classified as "less than R1000", "R1000 to R2500", "more than R2500 to R5000", "and more than R5000". The average monthly amount spent on alcohol and smoking was organised into "less than R500", "500 to 1000" and "more than 1000". These were both approximate values as neither group earned or spent money monthly but rather as the money was received.

Alcohol use. Alcohol use amongst the two informal worker groups was measured using the WHO Alcohol Use Disorder Identification Test (AUDIT) tool, a screening tool for hazardous and harmful alcohol consumption $(24,25)$. The AUDIT questionnaire has 10 questions which are divided into three groups. Questions 1-3 (frequency of drinking, the typical quantity of drinking, and frequency of heavy drinking) to assess hazardous alcohol use. Questions 4-6 (impaired control, increased salience of drinking, and morning drinking) to assess dependence symptoms. The last four questions 7-10 (contained guilt after drinking, blackouts, alcohol-related injuries, and concerns from others) assess the harmful effects of alcohol use (23).

The AUDIT score has a possible minimum score of zero for non- drinkers and a maximum score of forty. Based on previous research, two different scoring systems were used in this current study. The first scoring system used a score of $>=8$ to indicate a probable drinking problem and a score of $>=13$ to indicate probable alcohol dependence $(24,25)$. The second scoring system consists of four alcohol use levels: low risk (0-7 AUDIT score), high risk (8-15 AUDIT score), heavy drinking (16-19 AUDIT score), and hazardous drinking (20-40 AUDIT score) (25). However, in our analysis, "harmful drinking" was categorised as an AUDIT score of 16-40. Current drinking was defined as those who answered "yes" to the question "Do you drink alcohol?" or indicated a positive amount of alcohol consumed in the AUDIT tool, which was completed in all questionnaires.

Binge drinkers were categorised into "ever binge drank" and "frequent binge drinkers" using the question "How often do you have six or more standard drinks on one occasion?" from the AUDIT tool. Ever binge drank consisted of those participants who had had six or more standard alcohol drinks less than monthly. Frequent binge drinkers consisted of those participants who had had six or more standard alcohol drinks either monthly, weekly, or daily.

Mental Distress. WHO self-reporting questionnaire for common mental health disorders (CMD) (26) was used as a case-finding instrument in both the caddies and the waste pickers studies. The SRQ20 consists 
of 20 questions that assess neurotic (depression, anxiety, psychosomatic) symptoms (26). Each of the 20 items was scored 0 or 1 . A score of 1 indicated that the symptom was present during the past month; a score of 0 indicates that the symptom was absent. The maximum score is therefore 20 . A score of $\geq 8$ indicates the presence of mental distress $(11,26)$.

\section{Data Analysis}

All statistical analyses were conducted in STATA 16 (Stata Corp LLC, USA). Descriptive statistics were used to describe and summarise variables and compare the two informal worker groups including means, standard deviations, medians, frequencies, and percentages. Possible effect modifiers or confounding variables included were age, informal work type, education, housing, monthly income, source of cooking energy and water, smoking, and mental distress score (SRQ 20).

An independent student t-test was used to determine significant differences in the mean alcohol use scores between caddies and waste pickers. A proportions test was used to compare differences of proportions in demographic information and AUDIT risk levels between the two groups of informal workers. The Chi-square test was used to test for an association between AUDIT risk levels and symptoms associated with CMD.

Univariate analyses on all variables were conducted and a significance level of $95 \%$ was assigned to all tests. A multivariate logistic regression model was used to explore the predictors of problematic drinking in informal workers. The first scoring system of the AUDIT tool was used in the multivariate analysis. The AUDIT score was coded into a bivariate variable with those scoring less than 8 , unlikely to have a drinking problem, and those with a score of 8 and greater were coded as having a probable drinking problem. The SRQ 20 score achieved by each respondent was used as a categorical variable. A backward regression method was used to determine the adjusted effect of different risk factors for problematic alcohol use in informal workers. Variables with $p<0.05$ in the univariate analysis were kept in the final model if they produced a positive change in the pseudo R2, and improvement in the Akaike's Information Criteria (AIC) and Bayesian information criterion (BIC). Variables considered important risk factors for problematic alcohol use were kept in the model regardless of $p$-value and AIC/BIC scores.

\section{Results}

\section{Population description}

A total of 514 male informal workers were interviewed. The study group had a median age of 38 years. The waste pickers were significantly younger than the caddies, with $48.3 \%$ less than 30 years old, while only $2.0 \%$ of caddies were less than 30 years old (proportion test $p<0.0001$, Table 1 ). Very few caddies $(1.6 \%)$ and waste pickers $(2.6 \%)$ had no formal education. Significantly, more waste pickers than caddies completed secondary school education, $84.5 \%$, and $70.3 \%$, respectively (proportion test $p=0.0001$ ). However, more caddies $(6.8 \%)$ than waste pickers $(1.1 \%)$ had tertiary education. Approximately $2.8 \%$ of 
caddies and $14.3 \%$ of waste pickers consenting to the survey were not South African but had come from neighbouring countries including Zimbabwe, Lesotho, and Mozambique.

\section{Working conditions}

Both caddying and waste picking are considered low-skill jobs and have poor working conditions. Both groups have no work benefits (e.g leave days, pension funds). Although caddies work for registered golf courses, they are not legally employed by the golf courses. Caddies do not have guaranteed salaries, they may get to the golf course and not work a single round of golf and therefore, earning no money for the day. The precarious nature of salaries in the informal sector makes caddies and waste pickers vulnerable to poverty and substance abuse.

\section{Socioeconomic status}

Describing socioeconomic status, the majority of caddies and waste pickers used electricity as their cooking source, although more caddies used electricity than waste pickers $(p<0.0001)$. Approximately $74.7 \%$ of caddies and $65.3 \%$ of waste pickers had access to municipal water in their houses or yards. There was a difference in the proportion of caddies (61.5\%) and waste pickers (53.2\%) who used flushing toilets in their households; however, the difference was not significant. The larger proportion of caddies (48.2\%) and waste pickers (54.3\%) earned between R1000 to R2500 a month. However, on average caddies earned more than waste pickers, each group earning a mean of R2837.94 and R1906.59, respectively. Despite this low income, $27.3 \%$ of caddies and $9.1 \%$ of waste pickers reported spending approximately R500 to R1000 a month on alcohol. This figure is approximate as the caddies and waste pickers did not earn or spend monthly and they needed to calculate an amount. 
Table 1

Shows the demographic information of the participants by job title

\begin{tabular}{|c|c|c|c|c|}
\hline Demographics & $\begin{array}{l}\text { Entire } \\
\text { sample } \\
(\mathrm{N}=514)\end{array}$ & $\begin{array}{l}\text { Caddies } \\
(\mathrm{N}=249)\end{array}$ & $\begin{array}{l}\text { Waste pickers }(\mathrm{N}= \\
265)\end{array}$ & P-value \\
\hline \multicolumn{5}{|l|}{ Age } \\
\hline$<30$ & $133(25.9 \%)$ & $5(2.0 \%)$ & $128(48.3 \%)$ & $\begin{array}{l}< \\
0.0001\end{array}$ \\
\hline $30-40$ & $133(25.9 \%)$ & 47 (18.9\%) & $86(32.5 \%)$ & 0.0004 \\
\hline $41-50$ & $108(21.0 \%)$ & $86(34.5 \%)$ & $22(8.3 \%)$ & $\begin{array}{l}< \\
0.0001\end{array}$ \\
\hline$>50$ & $120(23.4 \%)$ & $\begin{array}{l}109 \\
(43.8 \%)\end{array}$ & $11(4.2 \%)$ & $\begin{array}{l}<.0001 \\
0 .\end{array}$ \\
\hline \multicolumn{5}{|l|}{ Education } \\
\hline No schooling & $11(2.1 \%)$ & $4(1.6 \%)$ & $7(2.6 \%)$ & 0.4311 \\
\hline Primary school & $83(16.2 \%)$ & $53(21.3 \%)$ & $30(11.3 \%)$ & 0.0021 \\
\hline Secondary school & $399(77.6 \%)$ & $\begin{array}{l}175 \\
(70.3 \%)\end{array}$ & $224(84.5 \%)$ & 0.0001 \\
\hline Tertiary school & $20(3.9 \%)$ & $17(6.8 \%)$ & $3(1.1 \%)$ & 0.0008 \\
\hline Non-South African & $45(8.8 \%)$ & $7(2.8 \%)$ & $38(14.3 \%)$ & $<0.000$ \\
\hline \multicolumn{5}{|l|}{ Cooking source } \\
\hline Electricity & $394(76.7 \%)$ & $\begin{array}{l}222 \\
(89.2 \%)\end{array}$ & $172(64.9 \%)$ & $\begin{array}{l}<.0001 \\
0.000\end{array}$ \\
\hline Other & $120(23.3 \%)$ & $27(10.8 \%)$ & $93(35.1 \%)$ & $\dot{0} 0001$ \\
\hline \multicolumn{5}{|l|}{ Water source } \\
\hline Household tap & $359(69.8 \%)$ & $\begin{array}{l}186 \\
(74.7 \%)\end{array}$ & $173(65.3 \%)$ & 0.0203 \\
\hline Communal tap & $134(26.1 \%)$ & $57(22.9 \%)$ & 77 (29.1\%) & 0.1097 \\
\hline Other & $17(3.3 \%)$ & $4(1.6 \%)$ & $13(4.9 \%)$ & 0.0364 \\
\hline \multicolumn{5}{|l|}{ Housing } \\
\hline Formal housing & 307 (59.7\%) & $\begin{array}{l}174 \\
(69.9 \%)\end{array}$ & $133(50.2 \%)$ & <. 0001 \\
\hline
\end{tabular}




\begin{tabular}{|c|c|c|c|c|}
\hline Demographics & $\begin{array}{l}\text { Entire } \\
\text { sample } \\
(\mathrm{N}=514)\end{array}$ & $\begin{array}{l}\text { Caddies } \\
(\mathrm{N}=249)\end{array}$ & $\begin{array}{l}\text { Waste pickers }(N= \\
\text { 265) }\end{array}$ & P-value \\
\hline Informal housing & $204(39.7 \%)$ & $75(30.1 \%)$ & $129(48.7 \%)$ & $\begin{array}{l}< \\
0.0001\end{array}$ \\
\hline \multicolumn{5}{|l|}{ Type of toilet } \\
\hline Private flush toilet & $294(57.2 \%)$ & $\begin{array}{l}153 \\
(61.5 \%)\end{array}$ & $141(53.2 \%)$ & 0.0573 \\
\hline Communal flush toilet & $102(19.8 \%)$ & $72(28.9 \%)$ & $30(11.3 \%)$ & $\begin{array}{l}< \\
0.0001\end{array}$ \\
\hline Other & $65(12.7 \%)$ & $21(8.4 \%)$ & $44(16.6 \%)$ & 0.0052 \\
\hline \multicolumn{5}{|l|}{ Income } \\
\hline Less than 1000 & $100(19.5 \%)$ & $30(12.1 \%)$ & $70(26.4 \%)$ & $\begin{array}{l}<.0001 \\
0.00\end{array}$ \\
\hline 1000 to 2500 & $264(51.4 \%)$ & $\begin{array}{l}120 \\
(48.2 \%)\end{array}$ & $144(54.3 \%)$ & 0.1667 \\
\hline More than 2500 to 5000 & $118(23.0 \%)$ & $76(30.5 \%)$ & $42(15.9 \%)$ & 0.0001 \\
\hline More than 5000 & $32(6.23 \%)$ & $23(9.2 \%)$ & $9(3.4 \%)$ & 0.0065 \\
\hline Average income & R2360.4 & R2837.9 & R1906.6 & - \\
\hline \multicolumn{5}{|c|}{ Alcohol monthly expenditure } \\
\hline Less than 500 & $363(70.6 \%)$ & $\begin{array}{l}156 \\
(62.7 \%)\end{array}$ & $207(78.1 \%)$ & 0.0001 \\
\hline 500 to 1000 & $92(17.9 \%)$ & $68(27.3 \%)$ & $24(9.1 \%)$ & $\begin{array}{l}<.0001 \\
0.000\end{array}$ \\
\hline More than 1000 & $59(11.5 \%)$ & $25(10.0 \%)$ & $34(12.8 \%)$ & 0.3190 \\
\hline \multicolumn{5}{|l|}{ Lifestyle } \\
\hline Current Smokers & $381(74.1 \%)$ & $\begin{array}{l}158 \\
(62.0 \%)\end{array}$ & $223(84.2 \%)$ & $\begin{array}{l}<.0001 \\
0.001\end{array}$ \\
\hline Cigarette Smokers & $364(70.8 \%)$ & $\begin{array}{l}155 \\
(98.1 \%)\end{array}$ & 209 (93.7\%) & 0.0126 \\
\hline Dagga smokers & $157(30.5 \%)$ & 39 (24.7\%) & $118(52.9 \%)$ & $\begin{array}{l}<.0001 \\
0.00\end{array}$ \\
\hline Drug users & $25(4.9 \%)$ & 0 & $25(11.2 \%)$ & $\begin{array}{l}<.0001 \\
0.000\end{array}$ \\
\hline
\end{tabular}




\begin{tabular}{|lllll|}
\hline Demographics & $\begin{array}{l}\text { Entire } \\
\text { sample } \\
(\mathbf{N}=\mathbf{5 1 4})\end{array}$ & $\begin{array}{l}\text { Caddies } \\
\mathbf{( N = 2 4 9 )}\end{array}$ & $\begin{array}{l}\text { Waste pickers }(\mathbf{N}= \\
\mathbf{2 6 5})\end{array}$ & P-value \\
\hline Alcohol consumers & $281(54.7 \%)$ & $\begin{array}{l}172 \\
(69.1 \%)\end{array}$ & $109(40.8 \%)$ & 0.0001 \\
\hline $\begin{array}{l}\text { Common mental disorder (score } \\
\geq 8)\end{array}$ & $136(26.5 \%)$ & $61(24.5 \%)$ & $75(28.3 \%)$ & 0.3290 \\
\hline *Proportions test & & & & \\
\hline
\end{tabular}

\section{Substance use}

More caddies were alcohol consumers $(69.1 \%)$ than waste pickers $(40.8 \%)$ (proportions test $p<0.0001)$. In contrast, more waste pickers (84.2\%) admitted to currently smoking than caddies (62.0\%) (proportions test $p<0.0001)$. Almost all the caddies $(98.1 \%)$ and $93.7 \%$ of waste pickers $(93.7 \%)$ were cigarette smokers. However, more waste pickers admitted to smoking dagga $(52.9 \%)$ and other drugs $(11.2 \%)$ than caddies, where only $24.7 \%$ and $0 \%$ used dagga and other drugs, respectively (Table 1 ).

Of the 514 participants, $392(76.3 \%)$ provided answers to the AUDIT questionnaire. Of these, 137 participants (34.9\%) reported never drinking. Of the 281 (54.7\%) who reported ever drinking, 190 (67.6\%) participants indicated ever binge drinking, and 127 (45.2\%) were frequent binge drinkers monthly or more frequently (Table 2).

Table 2 shows the mean total AUDIT score, which was higher in caddies compared to waste pickers (7.38 and 3.76 respectively, test $p<0.0001)$. Caddies showed significantly higher mean scores for all alcohol consumption behaviours (see Table 2). There was no significant difference in alcohol dependence symptoms between caddies and waste pickers, who both had low scores. However, the difference in total probable alcohol dependence scores between groups was marginally significant (AUDIT score $\geq 13, p=$ 0.0596). Neither group was more at risk for a probable drinking problem (AUDIT score $\geq 8, p=0.6630$ ). However, mean scores for alcohol-related problems such as blackouts, injuries due to alcohol, and loved ones/doctors concerned were significantly higher in caddies than in waste pickers.

The majority of caddies (38.4\%) and waste pickers (51.4\%) who consumed alcohol were "risky" drinkers (AUDIT score of $8-15)$. However, waste pickers were significantly "riskier" than caddies $(p=0.0322)$. Our results also showed that waste pickers who consumed alcohol $(78.0 \%)$ were significantly more likely to binge drink than caddies $(62.8 \%)(p=0.0051)$. Even though waste pickers participated more in risky and binge drinking than the caddies, harmful drinking (AUDIT score of 16-40) was more prominent among caddies than waste pickers, $23.8 \%$, and $8.3 \%$, respectively $(p=0.0009)$. 
Table 2

Mean AUDIT scores achieved by caddies and waste pickers for each question and the total scores.

\begin{tabular}{|c|c|c|c|c|}
\hline Alcohol use & $\begin{array}{l}\text { Entire sample } \\
\mathrm{n}=514 \\
\text { Mean score } \\
\text { (SD) }\end{array}$ & $\begin{array}{l}\text { Caddies } \mathrm{N}= \\
249 \\
\text { Mean score } \\
\text { (SD) }\end{array}$ & $\begin{array}{l}\text { Waste pickers } \\
\mathrm{N}=265 \\
\text { Mean score } \\
\text { (SD) }\end{array}$ & P-value* \\
\hline \multicolumn{5}{|l|}{ Consumption behaviour } \\
\hline Frequency of drinking & $1.21(1.13)$ & $1.54(0.93)$ & $0.95(1.21)$ & $<0.0001$ \\
\hline Typical quantity & $1.30(1.18)$ & $1.42(1.18)$ & $1.11(1.16)$ & 0.0356 \\
\hline Frequency of heavy drinking & $1.21(1.24)$ & $1.42(1.30)$ & $0.99(1.13)$ & 0.0015 \\
\hline \multicolumn{5}{|l|}{ Dependence symptoms } \\
\hline Impaired control & $0.77(1.18)$ & $0.87(1.22)$ & $0.66(1.12)$ & 0.1040 \\
\hline Increase salience of drinking & $0.58(0.94)$ & $0.65(0.96)$ & $0.51(0.91)$ & 0.1940 \\
\hline Morning drinking & $0.66(1.14)$ & $0.73(1.16)$ & $0.58(1.10)$ & 0.2381 \\
\hline \multicolumn{5}{|l|}{ Alcohol-related problems } \\
\hline Guilt after drinking & $0.80(1.21)$ & $0.93(1.22)$ & $0.66(1.18)$ & 0.0537 \\
\hline Blackouts & $0.69(1.11)$ & $0.48(0.99)$ & $0.48(0.99)$ & 0.0012 \\
\hline Alcohol-related injuries & $0.59(1.15)$ & $0.95(1.43)$ & $0.19(0.44)$ & $<0.0001$ \\
\hline Others concerned & $0.83(1.41)$ & $1.36(1.73)$ & $0.24(0.44)$ & $<0.0001$ \\
\hline Total AUDIT score & $5.52(6.98)$ & $7.38(7.86)$ & $3.76(5.47)$ & $<0.0001$ \\
\hline \multicolumn{5}{|l|}{ Risk level (AUDIT score) } \\
\hline Alcohol consumers & $\begin{array}{l}\text { Entire sample } \\
(\mathrm{N}=281)\end{array}$ & $\begin{array}{l}\text { Caddies } \\
(\mathrm{N}=172)\end{array}$ & $\begin{array}{l}\text { Waste pickers } \\
(N=109)\end{array}$ & $\begin{array}{l}\text { P- } \\
\text { value** }\end{array}$ \\
\hline Probable drinking problem $(\geq 8)$ & $172(61.2 \%)$ & $107(62.2 \%)$ & $65(59.6 \%)$ & 0.6630 \\
\hline $\begin{array}{l}\text { Probable alcohol dependence ( } \geq \\
\text { 13) }\end{array}$ & $88(31.3 \%)$ & $61(35.5 \%)$ & $27(24.8 \%)$ & 0.0596 \\
\hline \multicolumn{5}{|l|}{ Risk level n (\%) } \\
\hline Low risk (0-7) & $109(38.8 \%)$ & $65(37.8 \%)$ & $44(40.4 \%)$ & $<0.6630$ \\
\hline Risky drinking (8-15) & $122(43.4 \%)$ & $66(38.4 \%)$ & $56(51.4 \%)$ & 0.0322 \\
\hline
\end{tabular}




\begin{tabular}{|c|c|c|c|c|}
\hline Alcohol use & $\begin{array}{l}\text { Entire sample } \\
\mathrm{n}=514 \\
\text { Mean score } \\
\text { (SD) }\end{array}$ & $\begin{array}{l}\text { Caddies } N= \\
249 \\
\text { Mean score } \\
\text { (SD) }\end{array}$ & $\begin{array}{l}\text { Waste pickers } \\
\mathrm{N}=265 \\
\text { Mean score } \\
\text { (SD) }\end{array}$ & P-value* \\
\hline Harmful drinking (16-40) & $50(17.8 \%)$ & $41(23.8 \%)$ & $9(8.3 \%)$ & 0.0009 \\
\hline Ever binge drank & $193(68.9 \%)$ & $108(62.8 \%)$ & $85(78.0 \%)$ & 0.0051 \\
\hline Frequent binge drinking & $130(46.4 \%)$ & $79(45.9 \%)$ & $51(46.8 \%)$ & 0.8319 \\
\hline \multicolumn{5}{|c|}{ *t-test between caddies and waste pickers } \\
\hline
\end{tabular}

\section{Mental health and alcohol use}

There was no significant difference in the prevalence of common mental disorders between the two groups of informal workers $(p=0.329)$ (Table 1$)$. In total, $26.2 \%$ of the participants had a score of 8 and greater and were therefore positive for mental distress. Of the participants who experienced mental distress, $44.8 \%$ were caddies and $55.1 \%$ were waste pickers (not in table). Workers with a higher level of alcohol risk generally reported more mental health condition symptoms (Table 3). Symptoms that were significantly different between the alcohol risk levels were shaking hands $(p=0.015)$, feeling nervous $(p=$ $0.028)$, trouble thinking clearly $(p=0.013)$, feeling unhappy $(p=0.033)$, difficulty making decisions $(p=$ $0.015)$, loss of interest in things $(p=0.031)$, suicidal thoughts $(p=0.008)$, and uncomfortable feelings in the stomach $(p=0.032)$. Poor appetite and difficulty in enjoying daily activities were marginally significant, 0.078 , and 0.099 , respectively. 
Table 3

Combined bivariate analysis of symptoms for mental health conditions and proportions in each AUDIT risk level

\begin{tabular}{|c|c|c|c|c|}
\hline \multirow{3}{*}{ Symptoms } & \multicolumn{4}{|l|}{ AUDIT score } \\
\hline & Low risk $(0-7)$ & High risk (8-15) & Heavy drinking (16-40) & P-value* \\
\hline & $n=109(66 \%)$ & $n=122(24 \%)$ & $n=50(10 \%)$ & \\
\hline Headaches often & 35 (32.1\%) & 47 (38.5\%) & $19(38.0 \%)$ & 0.653 \\
\hline Poor appetite & 30 (27.5\%) & 49 (40.2\%) & 22 (44.0\%) & 0.078 \\
\hline Sleep badly & $25(22.9 \%)$ & $35(28.7 \%)$ & $19(38.0 \%)$ & 0.147 \\
\hline Easily frightened & $29(26.6 \%)$ & $36(29.5 \%)$ & $18(36.0 \%)$ & 0.345 \\
\hline Hands shake & $12(11.0 \%)$ & $31(25.4 \%)$ & $15(30.0 \%)$ & 0.015 \\
\hline Feel nervous & 35 (32.1\%) & $59(48.4 \%)$ & $26(52.0 \%)$ & 0.028 \\
\hline Poor digestion & $25(22.9 \%)$ & $38(31.2 \%)$ & $21(42.0 \%)$ & 0.092 \\
\hline Trouble thinking clearly & $12(11.0 \%)$ & $35(28.7 \%)$ & $13(26.0 \%)$ & 0.013 \\
\hline Feel unhappy & $33(30.3 \%)$ & $57(46.7 \%)$ & $25(50.0 \%)$ & 0.033 \\
\hline Cry more than usual & $16(14.7 \%)$ & $20(16.4 \%)$ & $8(16.0 \%)$ & 0.504 \\
\hline $\begin{array}{l}\text { Difficulty in enjoying } \\
\text { daily activities }\end{array}$ & $31(28.4 \%)$ & $46(37.7 \%)$ & $24(48.0 \%)$ & 0.099 \\
\hline $\begin{array}{l}\text { Difficulty in making } \\
\text { decisions }\end{array}$ & $26(23.9 \%)$ & $40(32.8 \%)$ & $22(44.0 \%)$ & 0.015 \\
\hline Daily work suffering & $38(34.9 \%)$ & $46(37.7 \%)$ & $21(42.0 \%)$ & 0.511 \\
\hline $\begin{array}{l}\text { Unable to play a useful } \\
\text { part in life }\end{array}$ & $40(36.7 \%)$ & $35(28.7 \%)$ & $22(44.0 \%)$ & 0.163 \\
\hline Lost interest in things & $38(34.9 \%)$ & $52(42.6 \%)$ & $29(58.0 \%)$ & 0.031 \\
\hline Feel worthless & $35(32.1 \%)$ & $38(31.2 \%)$ & $21(42.0 \%)$ & 0.274 \\
\hline Thought of ending life & $13(11.9 \%)$ & $5(4.1 \%)$ & $4(8.0 \%)$ & 0.008 \\
\hline Tired all the time & $14(12.8 \%)$ & $18(14.6 \%)$ & $4(8.0 \%)$ & 0.252 \\
\hline $\begin{array}{l}\text { Uncomfortable feelings } \\
\text { in stomach }\end{array}$ & $18(16.5 \%)$ & 39 (32.0\%) & 15 (30.0\%) & 0.032 \\
\hline
\end{tabular}

${ }^{*}$ Chi-square test 


\begin{tabular}{|lllll|}
\hline \multicolumn{4}{|c|}{ AUDIT score } & \\
\hline Easily tired & $23(21.1 \%)$ & $42(34.4 \%)$ & $19(38.0 \%)$ & 0.113 \\
\hline${ }^{*}$ Chi-square test & & & \\
\hline
\end{tabular}

There was a significant relationship between mental distress and risky and harmful drinking in this study (Chi-square test, $p=0.005$ ) (Table 4), with the difference in proportions increasing as the audit score increased. A significant association between smoking and mental distress was also found (Chi-square $p$ $=0.003$ ) despite the high proportion of current smokers.

Table 4

The association between mental distress, levels of drinking, and smoking status in informal workers

\begin{tabular}{|c|c|c|c|}
\hline & SRQ20 CMD Score & & P-value* \\
\hline AUDIT Score Levels $(n=281)$ & Low risk (<8) 203 (72.2\%) & Low risk $(\geq 8) 78(27.8 \%)$ & \\
\hline \multicolumn{4}{|l|}{ Limited to drinkers } \\
\hline Low Risk & $84(41.4)$ & $18(23.1)$ & \multirow[t]{3}{*}{0.003} \\
\hline Risky Level & $84(41.4)$ & $36(46.2)$ & \\
\hline Harmful drinking & $35(17.2)$ & $24(30.8)$ & \\
\hline Smoking $(n=502)$ & Low risk (<8) 366 (72.9\%) & Low risk ( $\geq 8) 136(27.1 \%)$ & \\
\hline \multicolumn{4}{|l|}{ Current smoker } \\
\hline Yes & $265(72.4)$ & $116(85.2)$ & \multirow[t]{2}{*}{0.003} \\
\hline No & $101(27.6)$ & $20(14.7)$ & \\
\hline Dagga smoker $(n=381)$ & Low risk (<8) & Low risk $(\geq 8) 116$ (30.4\%) & \\
\hline Limited to current smokers & $265(69.6 \%)$ & & \\
\hline Yes & $109(41.1)$ & $48(41.3)$ & \multirow[t]{2}{*}{0.964} \\
\hline No & $156(58.9)$ & $68(58.6)$ & \\
\hline
\end{tabular}

\section{Risk factors associated with probable problematic alcohol use}

The association between probable alcohol problem (AUDIT score $\geq 8$ ) and predictors that were selected from previous research is described in Table 5?. In the unstratified regression, $\mathrm{CMD}$ score $(\mathrm{aOR}=1.06$; $95 \% \mathrm{Cl}: 0.18-0.59)$, age, smoking $(\mathrm{aOR}=2.25 ; 95 \% \mathrm{Cl}: 1.34-3.79)$, and other water sources $(\mathrm{aOR}=0.2$; 
$95 \% \mathrm{Cl}$ : 0.04-0.99) were associated with a probable alcohol problem (AUDIT score $\geq 8$ ) amongst informal workers. The odds of having a probable alcohol problem was two times higher among informal workers between the ages of 30 to 40 years $(\mathrm{aOR}=2.06 ; 95 \% \mathrm{Cl}$ : $1.18-3.97)$ and 41 to 50 years $(\mathrm{aOR}=2.05$; $95 \% \mathrm{Cl}: 0.97-4.34)$, compared to workers younger than 30 years. The unstratified regression results also showed that waste pickers $(\mathrm{aOR}=0.33 ; 95 \% \mathrm{Cl}: 0.20-0.70)$ were less likely to be problematic drinkers compared to caddies (Table 5).

In the stratified multivariate regression for caddies, $\mathrm{CMD}$ score $(\mathrm{aOR}=1.16 ; 95 \% \mathrm{Cl}: 1.05-1.27)$ and smoking $(\mathrm{aOR}=3.58 ; 95 \% \mathrm{Cl}: 1.61-7.94)$ remained significant risk factors for a probable alcohol problem. Among waste pickers being between the ages of 30 and 40 years old $(\mathrm{aOR}=1.92 ; 95 \% \mathrm{Cl}$ : $1.01-3.66)$ was associated with problematic drinking. 
Table 5

Unstratified and stratified multivariate logistic regression of probable drinking problem predictors for caddies and waste pickers

\begin{tabular}{|c|c|c|c|c|c|c|}
\hline Risk predictors & $\begin{array}{l}\text { Entire } \\
\text { sample } \\
\text { aOR (P- } \\
\text { value) }\end{array}$ & $95 \% \mathrm{Cl}$ & $\begin{array}{l}\text { Caddies } \\
\text { aOR (P- } \\
\text { value) }\end{array}$ & $95 \% \mathrm{Cl}$ & $\begin{array}{l}\text { Waste } \\
\text { pickers } \\
\text { aOR (P- } \\
\text { value) }\end{array}$ & $95 \% \mathrm{Cl}$ \\
\hline CMD score & $\begin{array}{l}1.06 \\
(0.021)\end{array}$ & $\begin{array}{l}0.18- \\
0.59\end{array}$ & $\begin{array}{l}1.16 \\
(0.001)\end{array}$ & $1.05-1.27$ & $\begin{array}{l}0.96 \\
(0.261)\end{array}$ & $\begin{array}{l}0.89- \\
1.03\end{array}$ \\
\hline Age (years) & Ref & $\begin{array}{l}1.18- \\
3.97\end{array}$ & Ref & $\begin{array}{l}0.096- \\
27.96\end{array}$ & Ref & $\begin{array}{l}1.01- \\
3.66\end{array}$ \\
\hline $\begin{array}{l}<30 \\
30-40\end{array}$ & $\begin{array}{l}2.17 \\
(0.012)\end{array}$ & $\begin{array}{l}0.97- \\
4.34\end{array}$ & $\begin{array}{l}1.64 \\
(0.732)\end{array}$ & $\begin{array}{l}0.11- \\
27.63\end{array}$ & $\begin{array}{l}1.92 \\
(0.047)\end{array}$ & $\begin{array}{l}0.44- \\
2.97\end{array}$ \\
\hline $41-50 />50$ & $\begin{array}{l}2.05 \\
(0.060)\end{array}$ & $\begin{array}{l}0.49- \\
2.48\end{array}$ & $\begin{array}{l}1.71 \\
(0.706)\end{array}$ & $\begin{array}{l}0.06- \\
17.59\end{array}$ & $\begin{array}{l}1.15 \\
(0.779)\end{array}$ & \\
\hline$>50$ & $\begin{array}{l}1.11 \\
(0.806)\end{array}$ & & $\begin{array}{l}1.03 \\
(0.982)\end{array}$ & & & \\
\hline House type & - & - & - & & - & \\
\hline HIV & - & - & - & & - & \\
\hline Smoking & $\begin{array}{l}2.25 \\
(0.002)\end{array}$ & $\begin{array}{l}1.34- \\
3.79\end{array}$ & $\begin{array}{l}3.58 \\
(0.002)\end{array}$ & $1.61-7.94$ & $\begin{array}{l}1.01 \\
(0.976)\end{array}$ & $\begin{array}{l}0.41- \\
2.51\end{array}$ \\
\hline Electricity & - & & - & & $\begin{array}{l}1.62 \\
(0.244)\end{array}$ & $\begin{array}{l}0.72- \\
3.66\end{array}$ \\
\hline \multicolumn{7}{|l|}{ Water source } \\
\hline House tap & Ref & & Ref & & Ref & \\
\hline \multirow{2}{*}{$\begin{array}{l}\text { Communal tap } \\
\text { Other }\end{array}$} & $\begin{array}{l}0.93 \\
(0.771)\end{array}$ & $\begin{array}{l}0.58- \\
1.49\end{array}$ & $\begin{array}{l}1.17 \\
(0.709)\end{array}$ & \multirow{2}{*}{$\begin{array}{l}0.51-2.69 \\
0.02-2.82\end{array}$} & \multirow{2}{*}{$\begin{array}{l}- \\
0.91 \\
(0.815)\end{array}$} & \multirow[t]{2}{*}{$\begin{array}{l}0.60- \\
2.28\end{array}$} \\
\hline & $\begin{array}{l}0.20 \\
(0.049)\end{array}$ & $\begin{array}{l}0.04- \\
0.99\end{array}$ & $\begin{array}{l}0.21 \\
(0.237)\end{array}$ & & & \\
\hline Average income & $\begin{array}{l}0.99 \\
(0.765)\end{array}$ & $\begin{array}{c}0.99 \\
-1.00\end{array}$ & $\begin{array}{l}1.00 \\
(0.920)\end{array}$ & $0.99-1.00$ & $\begin{array}{l}0.99 \\
(0.700)\end{array}$ & $\begin{array}{l}0.99- \\
1.00\end{array}$ \\
\hline Work stress & $\begin{array}{l}1.12 \\
(0.748)\end{array}$ & & $\begin{array}{l}0.88 \\
(0.760)\end{array}$ & $0.39-2.00$ & & \\
\hline \multirow{2}{*}{$\begin{array}{l}\text { Type of informal } \\
\text { work }\end{array}$} & Ref & \multirow{2}{*}{$\begin{array}{l}0.20- \\
0.70\end{array}$} & \multirow[t]{2}{*}{-} & \multirow[t]{2}{*}{-} & \multirow[t]{2}{*}{-} & \\
\hline & $\begin{array}{l}0.33(< \\
0.001)\end{array}$ & & & & & \\
\hline Waste pickers & & & & & & \\
\hline
\end{tabular}




\section{Discussion}

This study aimed to assess problematic alcohol use and risk factors among informal workers in South Africa, as few studies have looked at alcohol abuse and mental health simultaneously in informal workers. Identifying the risk factors that are associated with substance abuse amongst informal workers is important to inform interventions made by policymakers to improve the working conditions of informal workers and protect marginalized and vulnerable populations.

Our analysis consisted of male informal workers who worked as caddies or waste pickers in Johannesburg, South Africa. We ascertained from the results of the interviews that over half of the informal workers in the study were alcohol consumers (54\%) this is substantially higher than the figure for the South African general population of $31 \%$ (12), and $26.2 \%$ were positive for mental distress (based on the results of the SRQ 20). Our results also showed that amongst other factors common mental disorders were associated with problematic drinking among informal workers (Table 5). However, the relationship between alcohol use and mental distress is a complex one, and we cannot ignore the reverse causality that may occur between problematic alcohol use and mental health disorders (27). This may call for a specific tool that uses symptoms independent of excess alcohol consumption in identifying mental distress in harmful drinkers.

In 2016, the WHO reported that SA had a relatively high alcohol abstention rate (abstaining from drinking for at least 12 months) (69\%), however, the relatively smaller percentage of the population that consumes alcohol (31\%), are mostly binge drinkers (consuming 60 grams or more of pure alcohol on at least one occasion over 30 days) (12). Similar to the WHO findings, the majority of alcohol consumers among informal workers in this study, $54 \%$, which was higher than the national figure of $31 \%$ were binge drinkers $(68.9 \%)$. This may be related to the precarious nature of their income.

This may be attributed to the difficult working conditions and financial stress they are subjected to (14). A majority $(70 \%)$ of the informal workers in our study earned R2500 per month which is well below the legislated minimum wage of R3300 for 8-hour shifts placing them in the poor group. The work of Mukong et al., 2017, provides evidence that the high prevalence of smoking (43.4\%) and alcohol consumption (43.4\%) among the "poorest" and "poor" in South Africa contributes to the income-related health inequality seen in South Africa (16).

This study found that problematic alcohol use was linked to the type of informal work, mental distress, age, source of water supply, and smoking among informal workers. From our analysis, we found that the average income of the informal workers was a possible confounder for the type of water source they had in their households. Informal workers who did not have running water in their households were less likely to be problem drinkers. This could be because they cannot afford to drink regularly and/or excessively.

When stratified by type of informal work, both mental distress and smoking were associated with a probable drinking problem in caddies. While in waste pickers, only age was associated with probable problematic use of alcohol. The caddies were significantly older than the waste pickers and their 
difference in alcohol consumption is suggestive of different coping mechanisms used to deal with the challenges and problems encountered in life.

Coping motives have been associated with problem drinking and drug abuse across diverse populations $(28-31)$. This means that the motives for substance use or abuse differ between populations and individuals. Coping skills may include behavioural disengagement, denial, mental disengagement, and substance use (32). To cope with stresses, caddies were more likely to turn to drinking while most waste pickers turned to binge drinking, smoking, and the use of other illicit drugs (Table 1). These different coping mechanisms can be attributed to the difference in age, as there was no significant difference in the proportion of caddies and waste pickers with mental distress (Table 1). Because waste pickers were generally younger than caddies, they were more open to exploring with other coping mechanisms other than alcohol to deal with their problems. Even though in our study smoking was not significantly associated with problematic drinking amongst waste pickers this may be due to the high proportion of smokers in the sample. In another study conducted amongst waste pickers, results showed that smoking was significantly associated with mental distress (23). Working conditions and the work setting may also influence the requirement of coping mechanisms (11).

Migrant informal workers in the United States of America stated that they often drank alcohol and smoked marijuana to escape feelings of sadness, loneliness, and work and life-related anxiety (14). We found similar results in our analysis, informal workers with higher AUDIT scores showed more symptoms for mental distress, these included shaking hands, feeling nervous, feeling unhappy, difficulty in making decisions, and loss of interest in day-to-day activities. However, it is important to note that the symptoms used for mental distress are non-specific and can be presented by individuals with alcohol-related problems (12). This makes it difficult to differentiate individuals with alcohol-use disorders or mental distress symptoms as they present with similar general complaints such as fatigue, insomnia, anxiousness, and sadness (22). Lack of security of employment, as well as less control of salaries, may contribute towards the risk of problematic drinking, substance use, and mental distress in informal workers $(11,33)$.

\section{Limitations}

Self-reported alcohol consumption and risk factors may well be subject to information bias. There was likely an underestimation of alcohol use and common mental disorders among these informal workers. Moreover, the absence of a clear alcohol-consumption use question in the waste pickers study could have led to lower responses to alcohol-related questions in the AUDIT questionnaire. Subsequently, this might have led to an underestimation of the number of alcohol consumers among waste pickers. Also, comparison of work stress between golf caddies and waste pickers may not be accurate due to the different definitions used in each respective study.

\section{Recommendations}


Future longitudinal studies could help better understand the relationship between alcohol use and mental distress in informal workers. Understanding problematic alcohol use and its risk factors in different populations require an understanding of the impact of different socioeconomic circumstances between different societal classes. Interventions, such as policy, health education/awareness, and support targeted at informal workers and those of lower socioeconomic status should be implemented to curb problematic alcohol use and smoking in these communities. Interventions to reduce and support mental distress may have an impact on substance abuse.

\section{Conclusion}

Common mental disorders, type of informal work, age, and smoking were associated with a probable alcohol problem amongst male informal workers in Johannesburg. However, when stratified by type of job, we reported differences in risk factors for problematic drinking between caddies and waste pickers. Informal workers of different ages might use different coping mechanisms for dealing with problems. Overall, working outside the protection of employment legislation is common in low- and middle-income countries and subsequently leads to socioeconomic inequalities, which may result in problematic alcohol use and mental health problems.

\section{Declarations}

\section{Ethics approval and consent to participate}

Ethics approvals for both studies were obtained from the University of the Witwatersrand Human Research Ethics Committee (Medical).

\section{Consent for publication}

All parties involved have given consent for publication.

\section{Competing interests}

There are no competing interests to disclose.

\section{Funding}

The National Institute of Occupational Health funded the studies.

\section{Authors' contributions}

Simbulele Mdleleni, the corresponding author for the research article was responsible for the data analysis and the interpretation and write-up of the data results. Dr. Kerry Wilson as the corresponding author's supervisor assisted with the concept development of the research article. Vusi Ntlebi, Felix Made, Tahira Kootbodien, Dr. Nonhlanhla Tlotleng, Matimba Makhubele, assisted with the data interpretation of 
the results and editing of the research article. Dr. Nisha Naicker as the head of the department was responsible for overseeing the completion of the paper.

\section{Acknowledgments}

We would like to acknowledge the informal worker committees on-site who through their support made this study successful.

\section{References}

1. Valodia I, Lebani L, Skinner C, Devey R. Low-waged and informal employment in South Africa. Transformation: Critical Perspectives on Southern Africa. 2006;60(1):90-126.

2. Peterson MM. Informal employment in South Africa: A critical assessment of its definition and measurement. An unpublished short dissertation, University of Pretoria. 2011 Dec.

3. Yu D. Defining and measuring informal employment in South Africa: A review of recent approaches. Johannesburg: DPRU. 2010 Oct 27.

4. Hart K. Informal income opportunities and urban employment in Ghana. The Journal of Modern African Studies. 1973 Mar;11(1):61-89.

5. StatsSA. Quarterly Labour Force Survey - Quarter 2: 2019. Q Labour Force Surv. 2019 Oct:1-70.

6. Garnett J, Made F, Tlotleng N, Wilson K, Naicker N. Work-Related Musculoskeletal Pain in Golf Caddies-Johannesburg, South Africa. International Journal of Environmental Research and Public Health. 2020 Jan;17(10):3617.

7. Inglis P. The "Caddie Question": Why the Golf Caddies of Bangalore Reject Formal Employment. Journal of Contemporary Ethnography. 2018 Oct;47(5):579-608.

8. Dlamini SQ. Solid waste management in South Africa: exploring the role of the informal sector in solid waste recycling in Johannesburg (Doctoral dissertation).

9. Dias SM. Waste pickers and cities. Environment and Urbanization. 2016 Oct;28(2):375-90.

10. Hayami Y, Dikshit AK, Mishra SN. Waste pickers and collectors in Delhi: poverty and environment in an urban informal sector. The Journal of Development Studies. 2006 Jan 1;42(1):41-69.

11. Ludermir AB, Lewis G. Informal work and common mental disorders. Social Psychiatry and Psychiatric Epidemiology. 2003 Sep 1;38(9):485-9.

12. World Health Organization. Global status report on alcohol and health 2018: Executive summary. World Health Organization; 2018.

13. Vellios NG, Van Walbeek CP. Self-reported alcohol use and binge drinking in South Africa: Evidence from the National Income Dynamics Study, 2014-2015. South African Medical Journal. 2018;108(1):33-9.

14. Negi NJ. Identifying psychosocial stressors of well-being and factors related to substance use among Latino day laborers. Journal of Immigrant and Minority Health. 2011 Aug 1;13(4):748-55. 
15. Duc DM, Vui LT, Quynh NT, Minh HV. Changes in co-occurrence of smoking and harmful drinking among youth: a study from the Chi Linh Demographic-Epidemiological Surveillance System in Vietnam, 2006-2013. Asian Pacific Journal of Cancer Prevention. 2016 May 1;17(S1):55-63.

16. Mukong AK, Van Walbeek C, Ross H. Lifestyle and income-related inequality in health in South Africa. International Journal for Equity in Health. 2017 Dec;16(1):103.

17. World Health Organization. Brief intervention for hazardous and harmful drinking: a manual for use in primary care. World Health Organization; 2001.

18. O'malley PM. Maturing out of problematic alcohol use. Alcohol Research \& Health. 2004;28(4):202.

19. Ko CH, Yen JY, Yen CF, Chen CS, Weng CC, Chen CC. The association between internet addiction and problematic alcohol use in adolescents: the problem behavior model. CyberPsychology \& Behavior. 2008 Oct 1;11(5):571-6.

20. World Health Organization. The ICD-10 classification of mental and behavioural disorders: clinical descriptions and diagnostic guidelines. Weekly Epidemiological Record= Relevé épidémiologique hebdomadaire. 1992;67(30):227.

21. Linden-Carmichael AN, Vasilenko SA, Lanza ST, Maggs JL. High-intensity drinking versus heavy episodic drinking: Prevalence rates and relative odds of alcohol use disorder across adulthood. Alcoholism: Clinical and Experimental Research. 2017 Oct;41(10):1754-9.

22. Schuckit MA. Alcohol-use disorders. The Lancet. 2009 Feb 7;373(9662):492-501.

23. Makhubele M, Ravhuhali K, Kuonza L, Mathee A, Kgalamono S, Made F, Tlotleng N, Kootbodien T, Ntlebi V, Wilson K, Naicker N. Common Mental Health Disorders among Informal Waste Pickers in Johannesburg, South Africa 2018-A Cross-Sectional Study. International Journal of Environmental Research and Public Health. 2019 Jan;16(14):2618.

24. 2 Saunders JB, Aasland OG, Babor TF, De la Fuente JR, Grant M. Development of the alcohol use disorders identification test (AUDIT): WHO collaborative project on early detection of persons with harmful alcohol consumption-II. Addiction. 1993 Jun;88(6):791-804.

25. Chen Y, Li X, Zhang C, Hong Y, Zhou Y, Liu W. Alcohol use and sexual risks: use of the Alcohol Use Disorders Identification Test (AUDIT) among female sex workers in China. Health Care for Women International. 2013 Feb 1;34(2):122-38.

26. Beusenberg M, Orley JH, World Health Organization. A User's guide to the self reporting questionnaire (SRQ). Geneva: World Health Organization; 1994.

27. World Health Organization Report. Harmful use of alcohol, alcohol dependence and mental health conditions: A review of the evidence for their association and integrated treatment approaches. 2019 May 24. [cited 2020 May 31] Available from: https://www.euro.who.int/en/health-topics/diseaseprevention/alcohol-use/publications/2019/harmful-use-of-alcohol,-alcohol-dependence-and-mentalhealth-conditions-a-review-of-the-evidence-for-their-association-and-integrated-treatment-approaches2019

28. Cooper ML, Russell M, Skinner JB, Frone MR, Mudar P. Stress and alcohol use: moderating effects of gender, coping, and alcohol expectancies. Journal of Abnormal Psychology. 1992 Feb;101(1):139. 
29. Kuntsche E, Knibbe R, Gmel G, Engels R. Why do young people drink? A review of drinking motives. Clinical Psychology Review. 2005 Nov 1;25(7):841-61.

30. Merrill JE, Thomas SE. Interactions between adaptive coping and drinking to cope in predicting naturalistic drinking and drinking following a lab-based psychosocial stressor. Addictive Behaviors. 2013 Mar 1;38(3):1672-8.

31. Park CL, Levenson MR. Drinking to cope among college students: prevalence, problems and coping processes. Journal of Studies on Alcohol. 2002 Jul;63(4):486-97.

32. Litman JA. The COPE inventory: Dimensionality and relationships with approach-and avoidancemotives and positive and negative traits. Personality and Individual Differences. $2006 \mathrm{Jul}$ 1;41(2):273-84.

33. Lemkow L. The employed unemployed: the subterranean economy in Spain. Social Science \& Medicine. 1987 Jan 1;25(2):111-3.

\section{Supplementary Files}

This is a list of supplementary files associated with this preprint. Click to download.

- CADDIESFINALETHICSAPPROVAL.pdf

- Wastepickerstudyethicsapproval.pdf 